\title{
Leaf Vein Density: A Possible Role as Cooling System
}

\author{
Mario Pagano and Paolo Storchi \\ Consiglio per la ricerca in agricoltura e l'analisi dell'economia agrarian-Unità di Ricerca per la Viticoltura Viale Santa Margherita, \\ Arezzo 80-52100, Italy
}

Received: July 9, 2015 / Accepted: July 30, 2015 / Published: July 30, 2015.

\begin{abstract}
The study of leaves and their architecture evolution is important for understanding the fluid dynamics of water movement in leaves. Recent studies have shown how these systems can be involved in the performance of physiological aspects, which are directly connected with the density of the vascular network and stomata per unit of surface area. The vein architecture, beyond being essential for a mechanical support of the leaf, can also play a crucial role in the efficiency of the photosynthesis. The aim of the present work was to highlight the possible role of leaves vein network as cooling system. The results support the hypothesis that the vascular system of grape leaves is correlated with leaf temperature.
\end{abstract}

Key words: Leaves, temperature, plant, vein density.

\section{Introduction}

Leaves are essential organs to maintain a correct balance between $\mathrm{O}_{2}$ and $\mathrm{CO}_{2}$ in the atmosphere through the processes of photosynthesis and breathing [1]. During the time, they have evolved a polyhedral anatomical structure, in which the veins are the heart of an organic evolution [2]. In fact, a physiological aspect, shared by other living organisms, is the high branching and structural diversity of the vascular system [3, 4]. Adjustment in the efficiency of water transport (i.e. the mass of water transported per unit of pressure gradient) is evident throughout the history of leaf evolutionary process. The structure of the xylem, able to increase hydraulic efficiency and to keep the continuity of the water column, has been crucial to the survival of the plant species in the course of time. The leaf vascular system has two main functions: transport of substance and mechanical support. Water, solutes and hormones through the xylem and carbohydrates, which are produced in the assimilating tissue of a leaf, are lead via the phloem [5]. The vein architecture, beyond being essential for a mechanical support of the leaf, can also

Corresponding author: Mario Pagano, Ph.D., research field: plant ecophysiology. E-mail: mario.pagano@entecra.it. play a crucial role in the efficiency of the photosynthesis $[2,6]$. In recent studies, daily values of leaves greenness as described by a colour index (e.g., excess green) were linked to seasonal changes in net ecosystem carbon dioxide exchange, canopy photosynthesis, and other important physiological measures [7, 8]. Red-green-blue brightness levels are influenced by scene illumination, but these influences can be suppressed by a nonlinear transform of RGB DN to RGB chromatic coordinates [9], defined as:

$$
\begin{aligned}
r_{c c} & =\frac{R}{(R+G+B)} \\
g_{c c} & =\frac{G}{(R+G+B)} \\
b_{c c} & =\frac{B}{(R+G+B)}
\end{aligned}
$$

During last two decades, numerous colour indices for digital images have been performed and explored especially in the scientific literature [10-12]. Based on manually taken nadir images of individual plants, the goal of many of these studies was improved distinction between green plants and soil/residue background prior to binarization [9-12]. The aim of the present work was to find a possible correlation between leaves vein network and leaf temperature. 


\section{Materials and Methods}

The research involved Vitis vinifera (L.), cultivar "Gorgottesco". Two-year-old vines was grafted onto $\mathrm{SO} 4(\mathrm{~V}$. berlandieri $\times \mathrm{V}$. riparia) rootstock. The vines were exposed to the same agricultural and environmental condition $\left(27.1{ }^{\circ} \mathrm{C} ; 64.1 \%\right.$ of relative humidity) inside the greenhouse in Arezzo, Italy. For each of six plants one leaves fully extended and developed in June 2015 were sampled from the main shoot. The mature leaves sample were selected with 40 days old according to the maximum photosynthesis rate [13]. Leaves temperature were performed, by a IR thermometer (Fluke $62 \mathrm{Mini}$ ), in the greenhouse with leaves still on the plant. Thermometer was set vertical to the sample and the leaf temperature was gained on three measurements for each leaf. Leaves temperature measurements were carried out between the midvein and margin. Leaves were sampled between sixth and seventh node of each main shoot. To ensure the selected material would have kept the freshness for the image analysis, each sample was temporarily placed in a refrigerated chamber at $4{ }^{\circ} \mathrm{C}$ for $24 \mathrm{~h}$ before the leaf image acquisition. Images were acquired using a EOS 700D camera (Canon, Japan) with EF $100 \mathrm{~mm} \mathrm{f} / 2.8$ Macro USM objective (Canon, Japan) and Dinolite digital microscope (AM-313T5, AnMo Electronics Corporation, Hsinchu, Taiwan) mounted over the LED light panel. The fresh sample was laid down on the top of the LED light panel. Leaves were stretched to allow the maximum focus rate during the image acquisition. The image acquisition of leaves shape were performed by Canon camera whereas, the leaves vein image were acquired by Dinolite microscope at 230x magnification. DinoXcope 1.9.9 (AnMo Electronics Corporation) was the software used for the veins acquisition. Microscope was set vertical to the sample and each image was collected with the optimal focus allowed by DinoXcope software. The image acquisition was performed by three $1 \mathrm{~mm}^{2}$ rectangles areas into a virtual grid. The rectangles were drawn to include at least two $2^{\circ}$ veins. For each leaf, the authors subsampled three rectangular boxes [4]. The boxes represented typical fragments and were located between the midvein and margin. Images were processed through the use of ImageJ $1.49 \mathrm{v}$ software (National Institutes of Health, USA). Dinolitemicroscope also allowed to collect crops necessary to build a 3D model of the vein network profile. The 3D model was performed using ImageJ software following this steps: Open image; 3D surface plot; Thermal LUT. This model is a possibility offered by ImageJ to simulate the heat distribution on leaves vein network.

\section{Results and Discussion}

The technique of image processing used in the present work has allowed obtaining information about vein networks of vine cultivars. Image processing method, shown, allows carrying out different kind of crops. Canon camera allowed to collect the whole size of the leaf, a fundamental step to know the leaf area. The authors found a significant correlation between the vascular system of grape leaves with leaf temperature (Fig. 1). This correlation support the hypothesis that the vascular system of grape leaves can assume a possible role during the leaf cooling. In fact, at higher leaf vein density correspond a lower temperature. In this direction, another study in Vitis vinifera (L.) [14] showed different vein density in two cultivars. Furthermore, in the work, the authors found a significant correlation between the leaves greenness index $\left(\mathrm{g}_{\mathrm{cc}}\right)$ and leaf temperature. Recent studies values of leaves greenness as described by a colour index (e.g., excess green) were linked to seasonal changes in net ecosystem carbon dioxide exchange, canopy photosynthesis, and other important physiological measures [7, 8]. The correlation (Fig. 2) show as at higher $g_{c c}$ value correspond lower temperature. Maybe, this information can be correlate to a good health of leaves. Furthermore, the authors found a significant correlation between the vein density and the leaves greenness index ( $\left.g_{c c}\right)$ (Fig. 3). This linear model maybe support the hypothesis as a high 


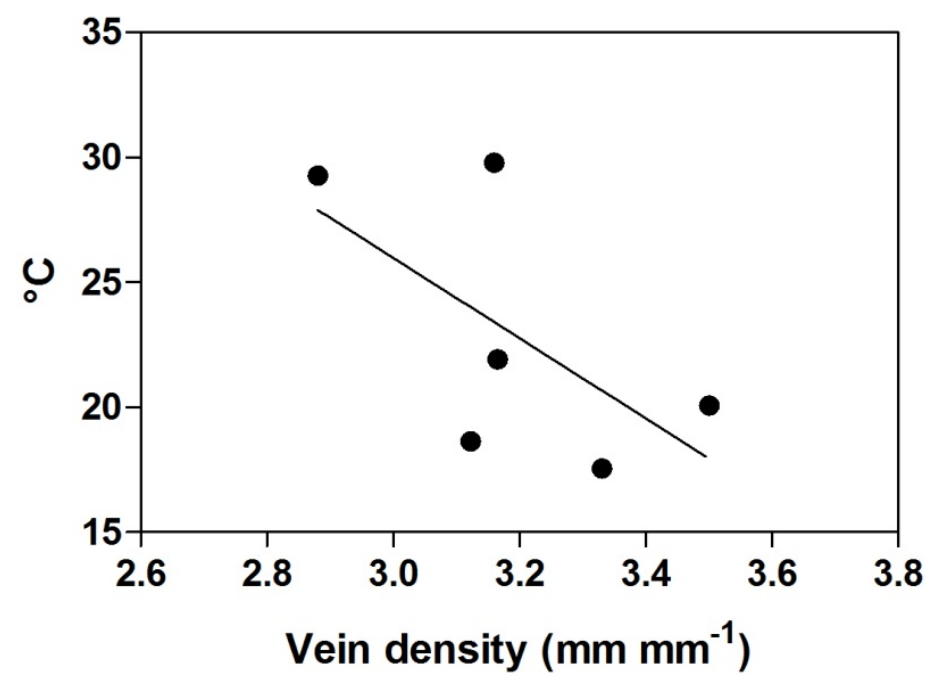

Fig. 1 Correlation between leaf vein density and leaf temperature $\left(P<0.01, r^{2}=0.39\right.$, no. $\left.=6\right)$.

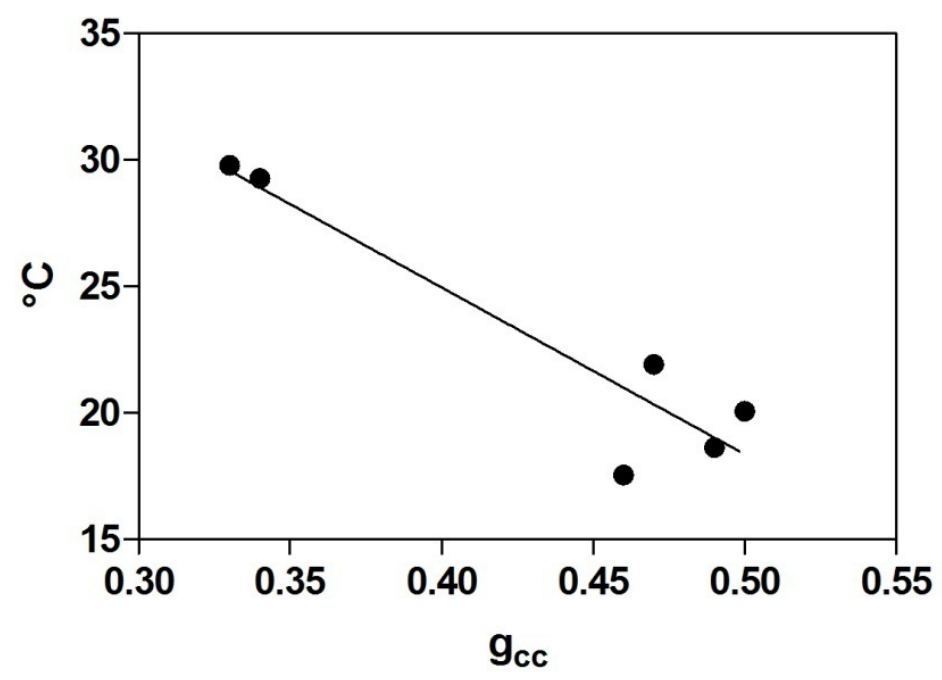

Fig. 2 Correlation between $g_{\mathrm{cc}}$ index and leaf temperature $\left(P<0.01, \mathrm{r}^{2}=0.86\right.$, no. $\left.=6\right)$.

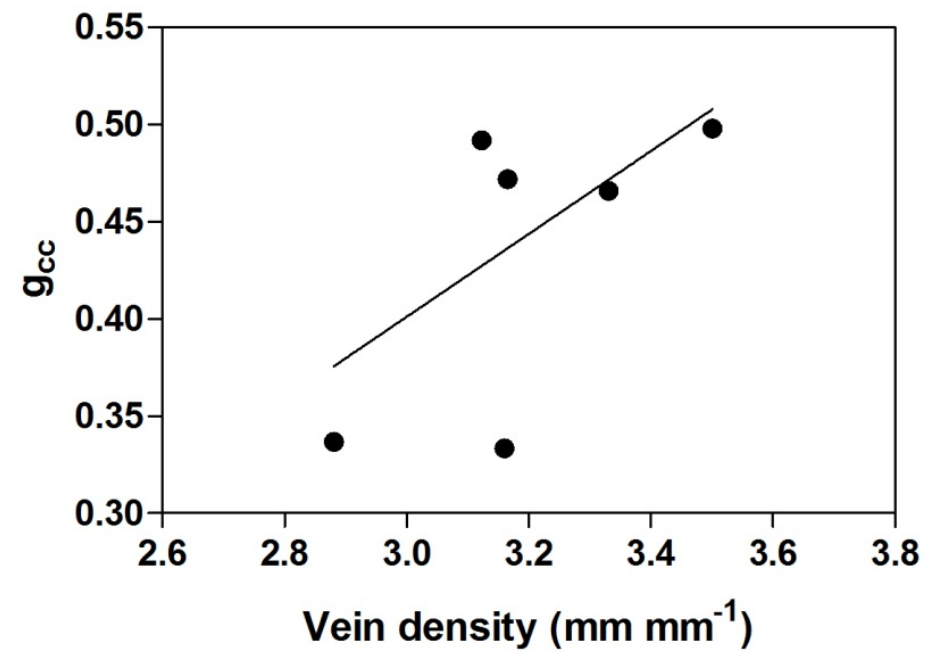

Fig. 3 Correlation between leaf vein density and $g_{c c}\left(P<0.01, r^{2}=0.36\right.$, no. $\left.=6\right)$. 


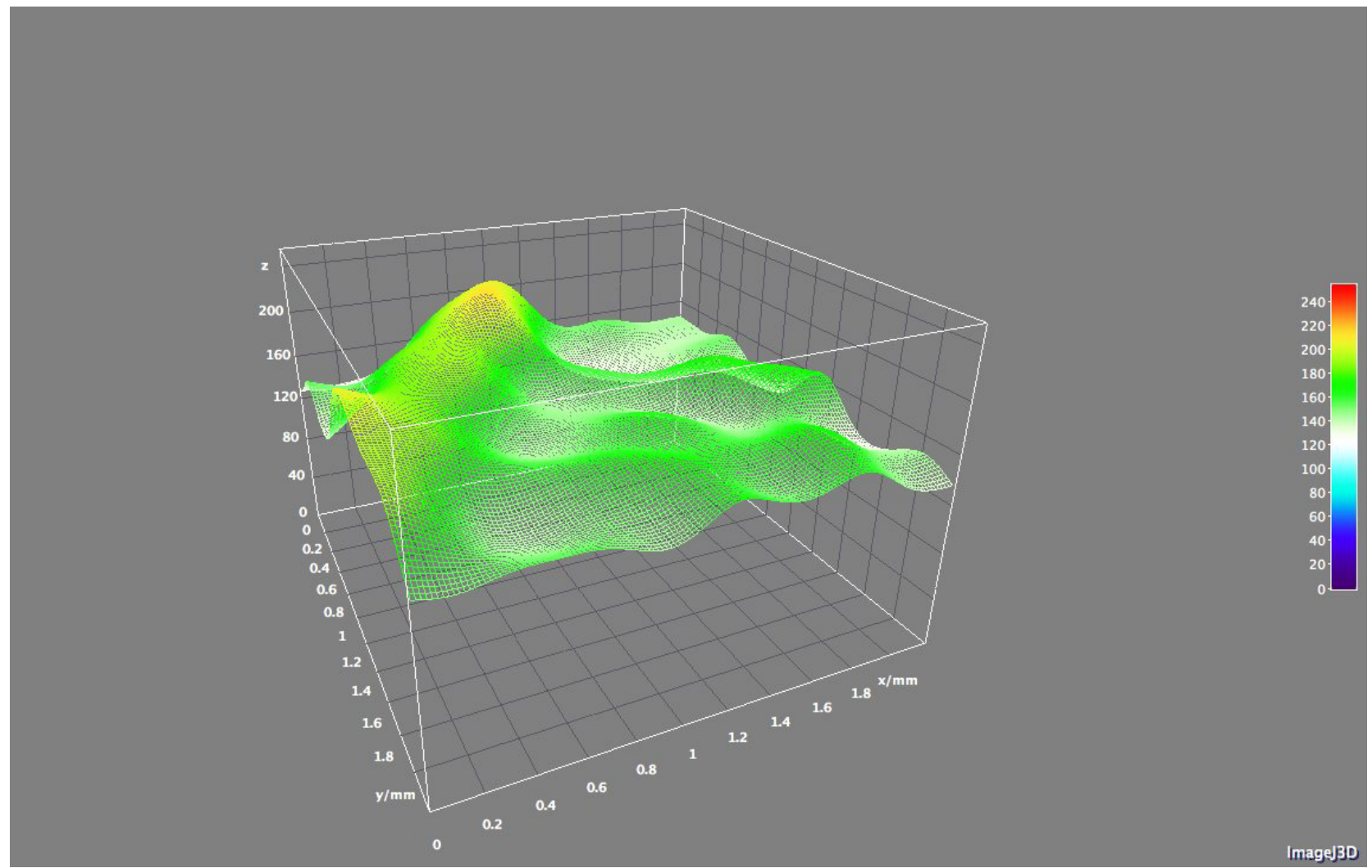

Fig. 4 Example of virtual thermal LUT of one crop. The 3D model was performed using ImageJ software following this step: Open image; 3D surface plot; Thermal LUT.

Table 1 RGB index of leaves crops.

\begin{tabular}{lllllll}
\hline & $\mathbf{R}$ & $\mathbf{G}$ & $\mathbf{B}$ & $\mathbf{r}_{\mathbf{c c}}$ & $\mathbf{g}_{\mathbf{c c}}$ & $\mathbf{b}_{\mathbf{c c}}$ \\
\hline Average & 119.50 & 146.41 & 92.49 & 0.34 & 0.43 & 0.23 \\
S.D. \pm & 42.39 & 25.13 & 66.09 & 0.02 & 0.08 & 0.08 \\
\hline
\end{tabular}

vascular system allows to keep the good greenness of leaves. A higher greenness index maybe consider similar a better content of cholorophyll. Using the Canon camera, ImageJ software and the RGB index (Table 1) were possible build a 3D model of the vein network (Fig. 4). The 3D LUT model allows to highlight the thermal vein profile using a specific colour spectrum.

\section{Conclusions}

The study of vein architecture is the main point to understand the fluid dynamics involved into the vascular tissues. The present work is a contribution to highlight the leaf vein network and its correlation with temperature. The authors measured the temperature width in each leaf sampled. Preliminary main data show a correlation between leaf vein density and temperature. The results support the hypothesis that the vascular system of grape leaves is correlated with leaf temperature. This correlation supports the hypothesis that the vascular system of grape leaves can assume a possible role during the leaf cooling. Next steps will be oriented to confirm this preliminary data using a thermal camera. In the future, it will be possible carry out predictive models that can integrate the knowledge gained through the "reading of the leaves": for example, to highlight the potential risk of water stress and the resulting demands for irrigation requirements in vineyard. Another aspect may be oriented to investigate which correlation exists between stomatal density per unit and vein density and how are linked to transpiration [15]. Use of the image analysis for 
characterization of the vein network in order to recognize the variety can be also conceived. Ultimately, the approach used in this study can be portability to similar species.

\section{References}

[1] Bhardwaj, A., Kaur, M., and Kumar, A. 2013. "Recognition of Plants by Leaf Image Using Moment Invariant and Texture Analysis." International Journal of Innovation and Applied Studies 1: 237-48.

[2] Brodribb, T. J., Field, T. S., and Jordan, G. J. 2007. "Leaf Maximum Photosynthetic Rate and Venation Are Linked by Hydraulics." Plant Physiology 144: 1890-8.

[3] Parsons-Wingerter, P., and Vickerman, M. B. 2011. "Informative Mapping by VESGEN Analysis of Venation Branching Pattern in Plant Leaves Such as Arabidopsis thaliana." Gravitational and Space Biology 25: 69-71.

[4] Sack, L., Scoffoni, C., McKown, A. D., Frole, K., Rawls, M., Havran, J. C., Tran, H., and Tran, T. 2012. "Developmentally Based Scaling of Leaf Venation Architecture Explains Global Ecological Patterns." Nature Communications DOI: 10.1038/ncomms1835.

[5] Roth-Nebelisck, A., Uhl, D., Mosbrugger, V., and Kerp, H. 2001. "Evolution and Function of Leaf Venation Architecture: A Review." Annals of Botany 87: 553-66.

[6] Sack, L., and Scoffoni, C. 2013. "Leaf Venation: Structure, Function, Development, Evolution, Ecology and Applications in the Past, Present and Future." New Phytologist 198: 983-1000.

[7] Ahrends, H. E., Etzold, S., Kutsch, W. L., Stoeckli, R., Bruegger, R., Jeanneret, F., Wanner, H., Buchmann, N., and Eugster, W. 2009. "Tree Phenology and Carbon Dioxide Fluxes: Use of Digital Photography at for
Process-Based Interpretation the Ecosystem Scale." Climate Research 39: 261-74.

[8] Richardson, A. D., Jenkins, J. P., Braswell, B. H., Hollinger, D. Y., Ollinger, S. V., and Smith, M. L. 2007. "Use of Digital Webcam Images to Track Spring Green-Up in a Deciduous Broadleaf Forest." Oecologia 152: 323-34.

[9] Sonnentag, O., Hufkens, K., Teshera-Sterne, C., Young, A. M., Friedl, M., Braswell, B. H., Milliman, T., O'Keefe, J., and Richardson, A. D. 2012. "Digital Repeat Photography for Phenological Research in Forest Ecosystems." Agricultural and Forest Meteorology 152: 159-77.

[10] Meyer, G. E., and Neto, J. C., 2008. "Verification of Colour Vegetation Indices for Automated Crop Imaging Applications." Computers and Electronics in Agriculture 63: 282-93.

[11] Perez, A. J., Lopez, F., Benlloch, J. V., and Christensen, S. 2000. "Colour and Shape Analysis Techniques for Weed Detection in Cereal Fields." Computers and Electronics in Agriculture 25: 197-212.

[12] Woebbecke, D. M., Meyer, G. E., Vonbargen, K., and Mortensen, D. A. 1995. "Colour Indexes for Weed Identification under Various Soil, Residue, and Lighting Conditions." Transactions of the ASAE 38: 259-69.

[13] Kriedemann, P. E., Kliewer, W. M., and Harris, J. M. 1970. "Leaf Age and Photosynthesis in Vitis vinifera (L.)." Vitis 9: 97-104.

[14] Pagano, M., and Storchi, P. 2015. "The Image Processing How Method to Investigate the Leaf Vascular Network: A First Study in Vitis vinifera (L.)." International Journal of Computer Engineering and Applications 6: 21-5.

[15] Brodribb, T. J. 2009. "Xylem Hydraulic Physiology: The Functional Backbone of Terrestrial Plant Productivity." Plant Science 177: 245-51. 